\title{
Correction to: High-frequency measurements of gas ebullition in a Brazilian subtropical reservoir-identification of relevant triggers and seasonal patterns
}

\author{
Lediane Marcon (D) Tobias Bleninger • \\ Michael Männich • Stephan Hilgert
}

Published online: 19 June 2019

(C) Springer Nature Switzerland AG 2019

Correction to: Environ Monit Assess (June 2019) 191:357

https://doi.org/10.1007/s10661-0197498-9

The original version of this article unfortunately did not contain all information in Figure 3. The dates in the graphs were missing in this figure.

The corrected Figure 3 is shown below.

The online version of the original article can be found at https://doi.org/10.1007/s10661-019-7498-9

L. Marcon $(\bowtie)$

Graduate Program on Water Resources and Environmental

Engineering (PPGERHA), Federal University of Parana (UFPR),

Curitiba, Brazil

e-mail: lediane.engambiental@gmail.com

T. Bleninger · M. Männich

Department of Environmental Engineering, Federal University of Parana, Curitiba, Brazil

S. Hilgert

Department of Aquatic Environmental Engineering, Institute for Water and River Basin Management, Karlsruhe Institute of Technology, Karlsruhe, Germany 

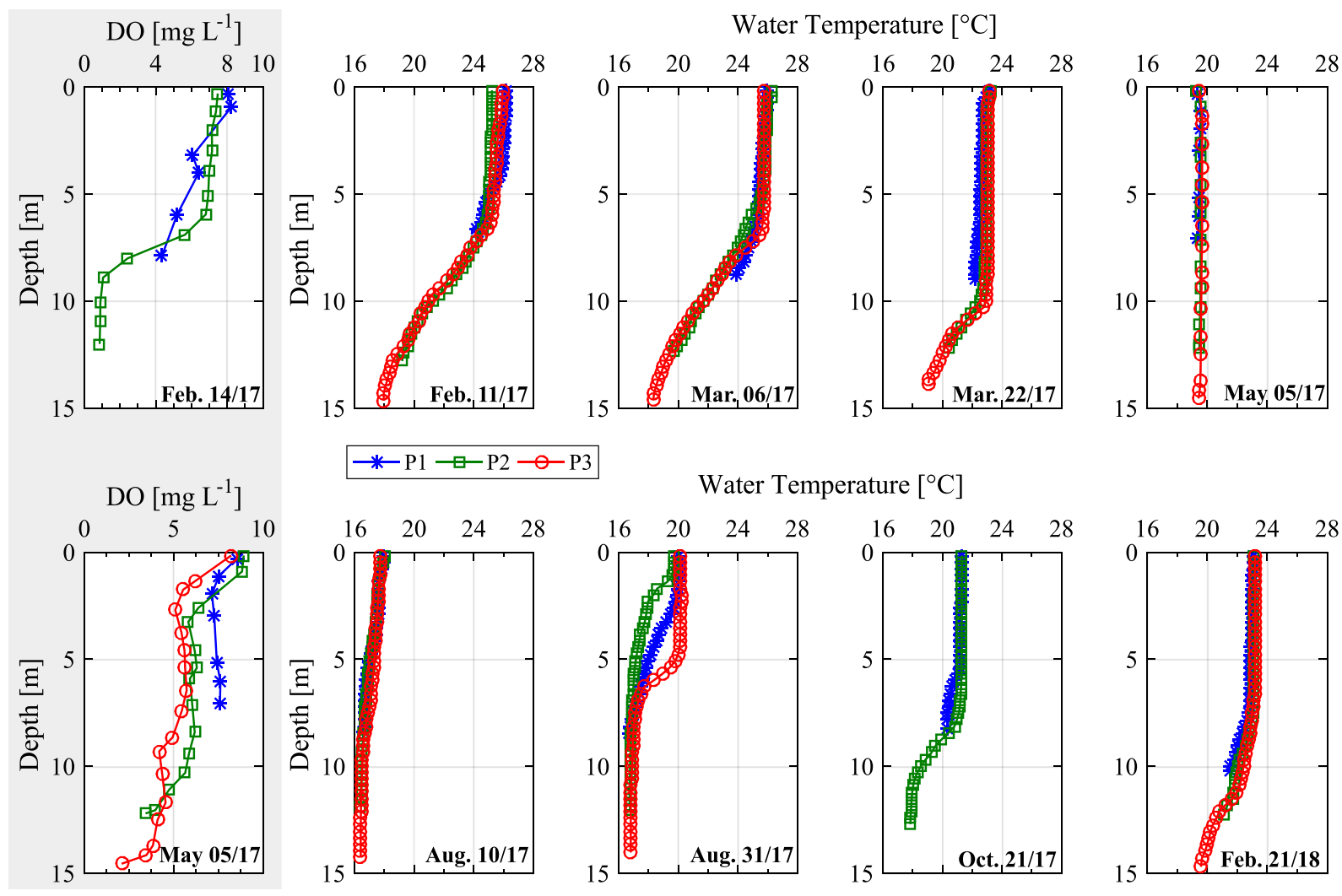

Water Temperature $\left[{ }^{\circ} \mathrm{C}\right]$

Fig. 3 Water temperature and dissolved oxygen (DO) profiles measured at ABTs location in 2017 and 2018. Except for that of May 2017, all temperature profiles were measured by a CTD
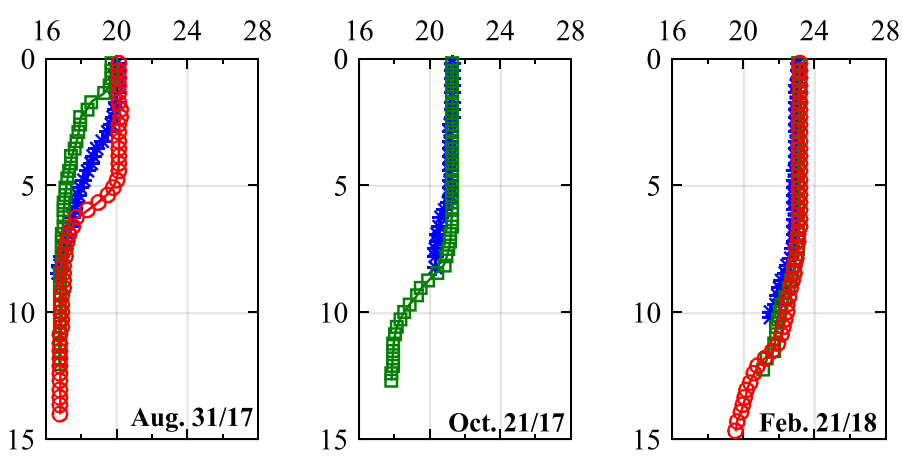

Sontek Castway. The dissolved oxygen profiles and the temperature in May 2017 were measured by a multiparameter probe

Publisher's note Springer Nature remains neutral with regard to jurisdictional claims in published maps and institutional affiliations. 